\title{
Using Improvisational Theater to Teach Genetics Concepts
}

\author{
Newcomb, Patricia PhD, RN CPNP \\ Riddlesperger, Kris PhD, RN, CNS
}

For 40 years, nursing leaders have called for more genetics content in the undergraduate nursing curriculum, but incorporating the essentials of the growing body of genetics knowledge into crowded nursing curricula remains a struggle. This case report describes an innovative strategy for assessing genetics content in a curriculum while providing a stimulating learning opportunity for students. Results suggest that using improvisational theater for teaching genetic concepts is an effective strategy and is well accepted by students.

Since including genetics in nursing curricula was first advocated by Brantl and Esslinger in $1962,{ }^{1}$ nursing leaders have frequently pointed out the increasing urgency of the endeavor. The 1998 revision of a guiding document for nursing education, The Essentials of Baccalaureate Education for Professional Nursing Practice, ${ }^{2}$ states that particular emphasis must now be placed on genetics, and in 2000, the Health Resources and Services Administration identified genetics as a foundational building block of nursing practice. ${ }^{3}$

The International Society of Nurses in Genetics agrees that genetics knowledge is relevant for all registered nurses, not only those involved in the care of individuals or populations affected by genetic disorders. Individual International Society of Nurses in Genetics members have developed curriculum frameworks and educational resources to promote the genetics/genomics competencies of all nurses. ${ }^{4}$ On a broader level, the $\mathrm{Na}$ tional Coalitional for Health Professional Education in Genetics calls for the inclusion of genetic information in the education of all healthcare professionals. ${ }^{5}$ Many professional nursing organizations are prominently represented in National

Authors' Affiliations: Director (Dr Newcomb), Genetics Translational Research Lab, University of Texas, Arlington; Lecturer (Dr Riddlesperger), Harris College of Nursing and Health Sciences, Texas Christian University, Fort Worth, Texas. Corresponding Author: Dr Newcomb, School of Nursing, Pickard Hall, University of Texas, Arlington, TX 76019

(pnewcombfellow@gmail.com).
Coalitional for Health Professional Education in Genetics and endorse the work of the consensus panel that established nursing genetic/genomic competencies based on the National Coalitional for Health Professional Education in Genetics framework. ${ }^{6}$

Although there is broad consensus regarding the importance of including genetics concepts in nursing education at the baccalaureate level, the most recent survey of genetics content in basic nursing programs in the United States showed that little genetics content existed in entry-level nursing curricula before $2000{ }^{7}$ The status of genetics in nursing curricula today is unknown, but may be improving because of efforts to educate nursing faculty by means of projects, such as the Web-Based Genetics Institute offered by the faculty at Cincinnati Children's Hospital and the annual National Institute of Nursing Research summer genetics institute. Both are educating nursing faculty who may be acting as change agents in their academic institutions. ${ }^{8}$

Motivated by a challenge from the faculty of the Cincinnati Children's WebBased Genetics Institute, the author surveyed her colleagues in the nursing faculty at a private, liberal arts university in the southwestern United States. Results of the survey indicated that genetics content was included in several courses in the undergraduate nursing curriculum, although the breadth and depth of such content were not clear. The school curriculum committee approved a trial of a genetics "capstone" project for students in the senior year. The purposes of this project were to discover gaps in knowledge, to provide students an opportunity to apply the genetics-related concepts acquired in various courses, and to test the feasibility of an innovative teaching strategy.

\section{Theater as Teaching Strategy}

Theater is a collaborative art form that has been informing audiences and actors at least since the ancient Greeks formalized performances in the 5th century BC. Improvisational theater is spontaneous, unscripted performance, which grows out of the actors' understanding of premises and context. The director of improvisational performances does not provide instructions for the actors, but assists the actors to reflect upon the performance. The power of theater as a tool for conveying information and commentary has been tested by time and the broadest imaginable replications, but it is rarely used in a planned way to teach or evaluate mastery of concepts to students in professional nursing programs. Most relevant work that has been reported explores the implementation of limited role play or individual patient simulation.

Role play in nursing education typically simulates an encounter between a single nurse and a single patient ${ }^{9}$ for the purpose of exploring interpersonal behaviors, expressing thoughts and feelings spontaneously, and acquiring new skills. This reflects the influence of published accounts of Jacob Moreno's ${ }^{10}$ "psychodrama" technique in the training of psychotherapists in the mid 20th century. 
This manuscript version is a rendition of the author's

prepublication copy. The version of record is available at the

publisher's website: http://journals.Iww.com/nurseeducatoronline

\section{Nurse Educator}

September/October 2007

Vol. 32(5), pp 227-230
Psychodrama focuses on teaching the helper to assist people to cope with or solve personal problems. Currently, much of the role play in nursing education is done with human simulators for purposes of teaching appropriate responses to physiological cues. This is invaluable training for nursing students, but does not address more complex sociocultural situations. Recognizing the importance of social issues for therapists, Moreno ${ }^{11}$ later developed a technique known as "sociodrama," which focuses on group relationships and social problems. Improvisational theater has the capacity to capture the complexity of psychodrama and sociodrama simultaneously and is an ideal complement to human simulator activities.

In addition to the interpersonal and social modeling that occurs in theater exercises, teaching by means of improvisational theater can also include elements of problem-based learning. This ensures that students are not limited to affective learning, but can acquire new concepts as well. Problem-based teaching methods in nursing education typically take the form of patient cases that present a problem to be solved by the student alone or in a group. The method requires the student to analyze the data presented in a case and then apply relevant concepts to solve the given problem. ${ }^{12}$ Recent studies in nursing education have demonstrated gains in critical thinking by students participating in problem-based learning compared with those exposed to standard didactic lectures ${ }^{13,14}$ and improvement in attitudes toward interprofessional collaboration. $^{15,16}$

\section{Methods}

The teaching exercise described here was based on the case of Molly Nash, which was news in 2001. ${ }^{17}$ Molly Nash was born with the genetic disorder, Fanconi anemia, which results in bone marrow failure. Stem cell transplantation from a perfectly matched donor is curative, and Molly's parents underwent in vitro fertilization (IVF) with preimplantation testing to produce a second child whose tissue match made a stem cell transplantation possible. The controversial case was thought to be recent enough to be relevant, but old enough that students would not be familiar with it.

Six students from a pediatric clinical practicum and seven from a maternity/women's health practicum participated. To decrease student anxiety, the exercise was referred to as a game and was not graded. The game was essentially a form of improvisational theater in which students assumed the roles of various characters involved in the selected case. In this case, students assumed the (fictional) roles of parents, genetic counselor, genetic nurse, obstetrician, obstetrical nurse, pediatric nurse, hematologist, ethics committee members, citizen groups, hospital administrators, and reporters. Roles were assigned randomly, and students were given brief, written descriptions of their characters and situations. They were given one initial direction designed to connect each one to another character, but were not given any other directions. No end goal was prescribed except to play until a "press conference" was convened several hours later.

Before game day, each student was given a set of readings to use as reference materials as noted in Figure 1. Roles were e-mailed to the students the day before the game. Host faculty arrived in a small ballroom on campus before the students to arrange tables and chairs in clusters. The clusters were identified with paper signs as the genetics clinic, the family home, the neighborhood coffee shop, the conference room used by the ethics committee, the library, the hospital administrators' conference room, and the pediatric clinic. Laptop computers with internet access were set up in the "library" space along with relevant textbooks and articles. Students could and did create additional spaces for new characters and activities.

An entire clinical day (6 hours) was set aside for the play. The morning began with a common "ice breaker" game based on the concept of genetic random assortment. Students were paired and given eight index cards each. Students wrote brief descriptions of "positive" traits of their own on half of the cards and "negative" traits on the other half. Students then shuffled their cards and drew half without seeing the descriptors to illustrate the random contribution of two partners in creating offspring.

Students were asked whether they preferred this randomness or whether they would rather have the control to choose the traits of their future offspring. After the discussion, the hosts framed the game as a case that contained a number of issues relevant to pediatric and maternity nursing, including the issue of genetic selection in the process of reproduction, genetic testing, Mendelian inheritance patterns, resources available for patients with genetic disorders and the professionals working with them, and social and ethical issues related to caring for families affected by genetic disorders or facing controversial reproductive decisions.

\section{Figure 1. Reference readings}

Methods Of Inheritance: Genetic Disorders And How They Are Passed From Generation To Generation. Genetics Program. Children's Helath, Texas Department of Health, 1100 West $49^{\text {th }}$ Street, Austin, TX, 78756

Stem Cell Information. National Institutes of Health. http://stemcells.nih.gov/info/basics/basics2 asp

Bone Marrow Transplantation and Peripheral Blood Stem Cell Transplantation: Questions and Answers. National Cancer Institute.

http://cis.nci.gov/fact/7 41/htm

Fanconi Anemia. GeneReviews. www.geneclinics.org

Scanlon G, Glover G. A professional code of ethics. Providing a moral compass for turbulent times. Oncology Nursing Forum, 22(10):1515-1521. 1995

Wolpert CM, Singer ML, Speer MC. Speaking the language of genetics: A primer. Journal of Midwifery and Women's Health, 50(33):184-188. 2005

Engstrom JL, Sefton MGS, Matheson JK, Healy KM. Genetic competencies essential for health care professionals in primary care. Journal of Midwifery and Women's Health, 50(3):177-183. 2005

Resnik DB. Genetic testing and primary care: A new ethic for a new setting. New Genetics and Society, 22(3). 2003 
This manuscript version is a rendition of the author's

prepublication copy. The version of record is available at the

publisher's website: http://journals.Iww.com/nurseeducatoronline
Nurse Educator

September/October 2007

Vol. 32(5), pp 227-230
Few of the students had an experience with sustained role playing, but most were able to remain in character throughout the entire period of the game. The students began tentatively with a few forays across the room into spaces that seemed relevant. The mother began her activities with a visit to the hematologist where she stated her directive, which was to inquire about options for treatment of her child. The "hematologist" then was faced with a problem: the need to deliver information to the mother. An appointment was made for a return visit, and the "hematologist" gathered information from the library resources while the mother went on to visit the obstetrician. "Administrators" began meeting and looking at the budget, which called for a drastic cut in spending that would entail eliminating programs. They reviewed all programs, including fetal medicine, stem cell transplantation, and IVF programs. The "ethics committee" met to consider a letter submitted by a hospital nurse objecting to the IVF program's perceived destruction of embryos and her request to review the possible "engineering" of offspring for the purpose of treating a patient. Other characters began to interact slowly with each other as suggested by the beginning directives. All decisions following the first directive belonged to the players, and the results were surprising.

Two "reporters" assumed the function of a Greek chorus and kept the group informed of developments. Each reporter represented a different newspaper. Large papered areas on two walls in the ballroom represented issues of the newspapers. As "news" was gathered, the reporters posted it on the "newspapers," and characters frequently reacted to news items in further decision making. The host faculty acted as telephone and e-mail, delivering messages between characters. Occasionally, hosts would interject an unexpected message, such as an anonymous call reacting to a character's decision or an intrahospital rumor. These interjections were rare but stimulated activity in spots that had temporarily stalled.

New characters emerged as the play progressed, including a state representative and an attorney representing the hospital where the mother worked. Citi- zen groups spontaneously organized around issues relating to preimplantation genetics testing and destruction of human embryos. The mother, unlike the real Mrs Nash, ultimately decided not to use IVF and preimplantation testing. The citizen group created a new character, the state representative, whom they invited to address the community regarding state allocations for stem-cell research. An attorney role was generated by a student in response to a lawsuit that was threatened.

Lunch was provided by the College of Nursing and Health Sciences and arrived in the middle of the action. Although they were not advised to remain in character, most of the students did so and participated by having lunch meetings with various characters, in which they attempted to persuade others to their point of view or worked on strategies for attaining their goals. By midafternoon, the game was brought to a close with a "press conference." During the press conference, the characters or representatives of different groups discussed their positions or their rationales for decisions they had made.

\section{Results}

\section{Gaps in Knowledge}

Through participant observation, host faculty obtained information to evaluate achievement of the proposed objectives: to discover gaps in student knowledge, to provide students an opportunity to apply genetics-related concepts acquired in various courses, and to test the feasibility of improvisational theater as a teaching strategy. Early in the game, it was clear that there were significant gaps in the knowledge base of the students. Students appeared to have no knowledge of formal ethical principles or social issues related to genetics. They had little or no knowledge about genetic nursing, genetic counseling, genetic resources, or genetic testing. They were aware of Mendelian inheritance patterns and understood IVF.

Although the students were expected to acquire or clarify concepts throughout the course of the performance, no specific learning objectives were formulated, and mastery of content was not formally tested. Consistent with the philosophy of clinical practicum at the institution, the performance was viewed as a capstone opportunity to apply concepts, not an alternative to a didactic lecture. However, the subjective perception of the success of the experiment suggests that such an alternative could reasonably be considered.

\section{Opportunity to}

\section{Apply Concepts}

The game provided an opportunity for students to acquire information about weak knowledge areas, discuss issues with people who had diverse viewpoints, and apply professional and practicerelated concepts in interactions with simulated clients, professionals, and laypersons. A number of students admitted they had never thought about some of the ethical issues involved or about their own values that underlie decisions they might have to make in similar circumstances. For some students, the process of debate, confrontation, or considering other viewpoints was usually uncomfortable; however, because of the "theater game" concept, they were able to use the assumed character as a protective vehicle, and none felt threatened enough to drop out.

\section{Feasibility of \\ Teaching Strategy}

At the end of the day, students were told that there were cards on the tables on which to write evaluations if they wished. Every student took the time to write an evaluation. Evaluations were uniformly positive and included suggestions for improving the game. Some comments included the following: "This was an excellent activity. I learned so much. Stem cell became so much more clear. I learned so much from the format of having the ethics committee, administration, etc. It is a very creative deal!" Another student commented, "I feel that it was a fabulous exercise, really stretched your brain and enforced rethinking your own values. I really felt my part and actually got very emotionally involved." A third student implied the lack of stimulation in traditional lectures when she stated, "I enjoyed the stimulation. It was interesting to learn the roles of hospital staff morally and ethically."

Acceptance by students was the major criteria for feasibility, but other issues included space, time, and faculty resources. The ballroom space used for this exercise 
This manuscript version is a rendition of the author's

prepublication copy. The version of record is available at the

publisher's website: http://journals.Iww.com/nurseeducatoronline

\section{Nurse Educator}

September/October 2007

Vol. 32(5), pp 227-230 was larger than the typical classroom and worked well because students had room to interact in large or small groups and to have privacy in their interactions while remaining visible. The time devoted to the exercise was 6 hours, but could have been pruned. Students became fatigued after lunch and were less productive then. Faculty included the two clinical instructors acting as hosts, as well as an interested faculty who participated as a member of the "ethics committee." A ratio of one faculty host to six to seven students was used here.

\section{Conclusion}

Experiential learning represents sound pedagogy. In this case, improvisational theater combines with problem-based learning as a powerful experiential teaching strategy. Students engaged quickly and remained engaged throughout the project. They encountered concepts that were unfamiliar and used the resources at hand to answer questions generated by themselves or peers. They constructed persuasive arguments to support ethical positions and demonstrated their grasp of the biological principles underlying the procedures they were considering. Incidentally, they also grappled with budgeting, allocation of resources, and personnel issues, including workman's compensation and right-to-work state policy. Although this exercise cannot substitute for integration of genetics content into the curriculum in a broad way, it proved to be a workable capstone-type vehicle for applying concepts in complex situations.

Schools of nursing, currently considering the benefits of simulation and other forms of experiential learning, should look closely at large-group, role-playing activity. Simulations are frequently associated with highly sophisticated electronic mannequins. However, the human group offers another simulacrum, which is even more powerful for complex issues. Improvisational theater, in particular, has much to offer as a way of simulating complex systems while keeping students safe as they gain competence. In this institution, including the "genetics game" as a part of all maternity and pediatric clinical groups is being seriously considered..

\section{References}

1. Brantl VM, Esslinger PN. Genetic implications for the nursing curriculum. Nurs Forum. 1962;1:90-100.

2. American Association of Colleges of Nursing. In: The Essentials of Baccalaureate Education for Professional Nursing. Washington, DC: AACN; 1998:7.

3. Health Resources and Services Administration. Report of the Expert Panel on Genetics and Nursing: Implications for Education and Practice. Washington, DC: Health Resources and Services Administration, National Institutes of Health; 2000.

4. Jenkins J. A historical perspective on genetic care. Online J Issues Nurs. 2000;5(3):mss2.

http://www.nursingworld.org/ojin/t opic13/tpc13 2.htm. Accessed September 29, 2006.

5. National Coalition for Health Professional Education in Genetics. Core Competencies in Genetics Essential for all Health Care Professionals. 2000. http://www.nchpeg.org/. Accessed November 21, 2006. [Context Link]

6. Consensus Panel on Genetic/ Genomic Nursing Competencies. Essential Nursing Competencies and Curricula Guidelines for Genetics and Genomics. Silver Spring, MD: American Nurses Association; 2006. http://www.nursingworld.org/ethics /genetics/geneticscomp.pdf. Accessed September 29, 2006.

7. Hetteberg CG, Prows CA, Deets C, Monsen RB, Kenner CA. National survey of genetics content in basic nursing preparatory programs in the United States. Nurs Outlook. 1999;47(4):168-174.

8. Prows CA, Latta KK, Hetteberg C, Williams JK, Kenner C, Monsen RB. Preparation of undergraduate nursing faculty to incorporate genetics content into curricula. Biol Res Nurs. 1999;1(2):108-112.

9. Shearer R, Davidhizer R. Using role play to develop cultural competencies. J Nurs Educ. 2003;42(6):273276.

10. Moreno JL. Psychodrama. Boston, MA: Beacon Press; 1946.

11. Moreno JL. Who Shall Survive? Beacon, NY: Beacon House; 1953.

12. Rideout E. Transforming Nursing Education Through Problem-Based Learning. Sudbury, MA: Jones and Bartlett; 2001.

13. Tiwari $A$, Lai $P$, So $M$, Kwan $Y$. A comparison of the effects of problem-based learning and lecturing on the development of students' critical thinking. Med Educ. 2006;40(6):547554.

14. ASHE-ERIC. Curriculum reforms in the professions: responding to calls for change. Higher Educ Rep. 2002;29(3):41-43.
15. Goelen G, De Clercq G, Huyghens L, Kickhofs E. Measuring the effect of interprofessional problem-based learning on the attitudes of undergraduate healthcare students. Med Educ. 2006;40(6):555-561.

16. Curran VR, Mugford JG, Law RMT, MacDonald S. Influence of an interprofessional HIV/AIDS education program on role perception, attitudes and teamwork skills of undergraduate health sciences students. Educ Health. 2005;18(1):32-44.

17. Rowland R. Associated Press. Genetic selection gives girl a brother and second chance. Cable News Network.

http://archives.cnn.com/2000/HEAL $\mathrm{TH} / 10 / 03 /$ testube.brother/2000. Accessed November 21, 2006. 